\title{
Intravascular hemolysis triggers ADP- mediated generation of platelet-rich thrombi in precapillary pulmonary arterioles
}

\author{
Tomasz Brzoska, ${ }^{1}$ Ravi Vats, ${ }^{1,2}$ Margaret F. Bennewitz, ${ }^{1,3}$ Egemen Tutuncuoglu, ${ }^{1}$ Simon C. Watkins, ${ }^{4}$ \\ Margaret V. Ragni, ${ }^{5}$ Matthew D. Neal, ${ }^{6}$ Mark T. Gladwin, ${ }^{1,7}$ and Prithu Sundd ${ }^{1,2,7}$ \\ 'Pittsburgh Heart, Lung and Blood Vascular Medicine Institute, University of Pittsburgh School of Medicine, Pittsburgh \\ Pennsylvania, USA. ${ }^{2}$ Department of Bioengineering, University of Pittsburgh, Pittsburgh, Pennsylvania, USA. ${ }^{3}$ Department \\ of Chemical and Biomedical Engineering, West Virginia University, Morgantown, West Virginia, USA. ${ }^{4}$ Center for Biologic \\ Imaging, University of Pittsburgh, Pittsburgh, Pennsylvania, USA. ${ }^{5}$ Department of Medicine, University of Pittsburgh, \\ Hemophilia Center of Western Pennsylvania, Pittsburgh, Pennsylvania, USA. ${ }^{6}$ Department of Surgery and ${ }^{7}$ Division of \\ Pulmonary Allergy and Critical Care Medicine, University of Pittsburgh School of Medicine, Pittsburgh, Pennsylvania, USA.
}

\begin{abstract}
Patients with hereditary or acquired hemolytic anemias have a high risk of developing in situ thrombosis of the pulmonary vasculature. While pulmonary thrombosis is a major morbidity associated with hemolytic disorders, the etiological mechanism underlying hemolysis-induced pulmonary thrombosis remains largely unknown. Here, we use intravital lung microscopy in mice to assess the pathogenesis of pulmonary thrombosis following deionized water-induced acute intravascular hemolysis. Acute hemolysis triggered the development of allb $\beta 3$-dependent platelet-rich thrombi in precapillary pulmonary arterioles, which led to the transient impairment of pulmonary blood flow. The hemolysis-induced pulmonary thrombosis was phenocopied with intravascular ADP- but not thrombin-triggered pulmonary thrombosis. Consistent with a mechanism involving ADP release from hemolyzing erythrocytes, the inhibition of platelet $P 2 Y_{12}$ purinergic receptor signaling attenuated pulmonary thrombosis and rescued blood flow in the pulmonary arterioles of mice following intravascular hemolysis. These findings are the first in vivo studies to our knowledge to suggest that acute intravascular hemolysis promotes ADPdependent platelet activation, leading to thrombosis in the precapillary pulmonary arterioles, and that thrombin generation most likely does not play a significant role in the pathogenesis of acute hemolysis-triggered pulmonary thrombosis.
\end{abstract}

Conflict of interest: The authors have declared that no conflict of interest exists.

Copyright: (ㄷ) 2020, American Society for Clinical Investigation.

Submitted: April 21, 2020

Accepted: June 11, 2020

Published: July 23, 2020.

Reference information: /CI Insight. 2020;5(14):e139437.

https://doi.org/10.1172/jci.

insight.139437.

\section{Introduction}

Hemolysis is one of the major pathophysiological events associated with inherited and acquired disorders such as sickle cell disease (SCD) (1-3), thalassemia $(1,4)$, paroxysmal nocturnal hemoglobinuria $(\mathrm{PNH})(5,6)$, thrombotic thrombocytopenic purpura (TTP) $(7,8)$, hemolytic-uremic syndrome (HUS) $(7,9)$, sepsis $(10,11)$, and malaria (12). Intravascular hemolysis promotes the release of erythrocyte-derived damage-associated molecular pattern molecules (eDAMPs) - including cell-free hemoglobin, heme, uric acid, and adenosine diphosphate (ADP) - that may directly and/or indirectly promote thrombosis, endothelial dysfunction, and sterile inflammation (13-17). Although pulmonary thrombosis is a major clinical morbidity affecting patients with hemolytic disorders, how intravascular hemolysis promotes thrombosis in the lung remains poorly understood (18-26).

Hemolysis is associated with hemostatic abnormalities such as enhanced platelet activation and thrombin generation, elevated circulating tissue factor, and endothelial injury (1, 3, 5, 9, 15, 27-32). Thrombocytopenia, which is suggestive of intravascular platelet sequestration, is a risk factor for acute systemic and pulmonary complications of hemolytic disorders (8, 32-34). Importantly, autopsy and CT studies have identified platelet-rich thrombi occluding pulmonary artery branches and arterioles in patients with diverse hemolytic disorders $(19,20,25,35,36)$. Taken together, these findings suggest that in situ platelet aggregation within the pulmonary vasculature may potentially contribute to acute hemolysis-induced pulmonary 
thrombosis. However, the in vivo evidence and the molecular mechanism of this pathophysiology have remained elusive. Here, we use quantitative fluorescence intravital lung microscopy (qFILM) to reveal that acute intravascular hemolysis triggers pulmonary thrombosis in mice, which is enabled by the occlusion of precapillary pulmonary arterioles by platelet-rich thrombi, leading to transient loss of blood flow in the lung. Our findings are the first in vivo studies to our knowledge to show that acute hemolysis-induced pulmonary thrombosis is largely mediated by ADP-dependent platelet purinergic signaling, leading to platelet activation and $\alpha \mathrm{IIb} \beta 3$-dependent platelet aggregation in the pulmonary arterioles.

\section{Results}

Intravascular hemolysis promotes platelet-dependent pulmonary arteriole thrombosis. qFILM revealed absence of pulmonary thrombosis in mice intravascularly administered saline (control mice). In control mice, blood (purple fluorescence) was observed to flow unobstructed through the pulmonary vasculature, with erythrocytes visible as rapidly transiting dark cells (Supplemental Figure 1 and Supplemental Video 1; supplemental material available online with this article; https://doi.org/10.1172/jci.insight.139437DS1). Previously, intravascular administration of deionized water $\left(\mathrm{dH}_{2} \mathrm{O}\right)$ has been shown to trigger acute intravascular hemolysis in mice in vivo (37). qFILM revealed that intravascular administration of $\mathrm{dH}_{2} \mathrm{O}$ triggered the development of platelet-rich thrombi (green fluorescence) in the precapillary pulmonary arterioles of mice (Figure 1 and Supplemental Video 2). As shown in Supplemental Video 2, these thrombi were primarily formed in the pulmonary arteriolar bottlenecks (junction of pulmonary arteriole and capillaries) and resolved entirely over the next 2 minutes, resulting in a transient impairment of pulmonary blood flow. The time series of qFILM images were analyzed over several mice to determine the kinetics of pulmonary thrombosis in terms of 3 separate parameters: total pulmonary thrombi area as a function of time (Figure 1B), maximum pulmonary thrombi area (red arrow in Figure 1B), and AUC (Figure 2D) as described in Methods. Next, we used eptifibatide, which is an antagonist of platelet receptor $\alpha \operatorname{IIb} \beta 3$ (38) and FDA-approved drug for the prevention of platelet aggregation-dependent thrombosis in a broad range of ischemic coronary conditions, including percutaneous coronary intervention, acute coronary syndrome, and unstable angina (38). Remarkably, pretreatment with $10 \mathrm{mg} / \mathrm{kg}$ intravascular eptifibatide completely abrogated intravascular $\mathrm{dH}_{2} \mathrm{O}$-triggered pulmonary thrombosis in mice (Figure 2, A and B, and Supplemental Video 3), which was evident by the significant reduction in both pulmonary thrombi maximum area (Figure 2, B and C) and AUC (Figure 2D). These findings indicate that pulmonary arteriole thrombosis triggered by acute intravascular hemolysis is predominantly dependent on platelet activation and subsequent aggregation.

Acute hemolysis-induced pulmonary thrombosis is unlikely to be thrombin dependent. Thrombin directly activates a number of coagulation factors, cleaves fibrinogen to fibrin, and stimulates protease activated receptors (PARs) on platelets to promote thrombosis $(39,40)$. Importantly, markers of thrombin generation, such as prothrombin fragment $\mathrm{F} 1+2$, thrombin-antithrombin III complexes, and D-dimers, have been found to be significantly elevated in diverse hemolytic disorders $(9,41-45)$. Therefore, we compared the pathophysiology of pulmonary thrombosis triggered by intravascular $\mathrm{dH}_{2} \mathrm{O}$ (acute hemolysis) to the one by intravascular thrombin. Unlike the transient pulmonary thrombosis triggered by acute hemolysis (Figure 1), mice challenged with $250 \mathrm{U} / \mathrm{kg}$ intravascular thrombin developed protracted pulmonary thrombosis, accompanied by the development of platelet-rich thrombi within the pulmonary arteriolar bottlenecks (Figure 3, A and C, and Supplemental Video 4). Subsequently, we examined the effect of 500 $\mathrm{U} / \mathrm{kg}$ intravascular thrombin on the pulmonary thrombosis development in mice. A total of $75 \%$ of mice challenged with higher dose of $500 \mathrm{U} / \mathrm{kg}$ intravascular thrombin died, which was also accompanied by the loss of the pulmonary blood flow (Figure 3, B, D, and E, and Supplemental Video 5). Unexpectedly, the average pulmonary thrombi maximum area in mice administered $500 \mathrm{U} / \mathrm{kg}$ intravascular thrombin was not significantly higher than mice administered $250 \mathrm{U} / \mathrm{kg}$ intravascular thrombin (Figure 3F), which was probably caused by the pulmonary thrombosis in large arterial branches $(>50 \mu \mathrm{m})$ upstream of pulmonary arterioles in mice administered $500 \mathrm{U} / \mathrm{kg}$ intravascular thrombin (Figure 3G and Supplemental Video 6). In contrast to the effect of eptifibatide on hemolysis-induced pulmonary thrombosis (Figure 2), eptifibatide failed to prevent severe pulmonary thrombosis (Figure 4, A and B, and Supplemental Video 7) and lethality (Figure 4C) following intravascular administration of $500 \mathrm{U} / \mathrm{kg}$ thrombin. The mean pulmonary thrombi maximum area in mice treated with eptifibatide before $500 \mathrm{U} / \mathrm{kg}$ intravascular thrombin was not different from mice treated with $500 \mathrm{U} / \mathrm{kg}$ intravascular thrombin only (Supplemental Figure 2), further suggesting that eptifibatide did not attenuate thrombin-triggered pulmonary arteri- 
A $\mathrm{dH}_{2} \mathrm{O} 150 \mu \mathrm{l}$

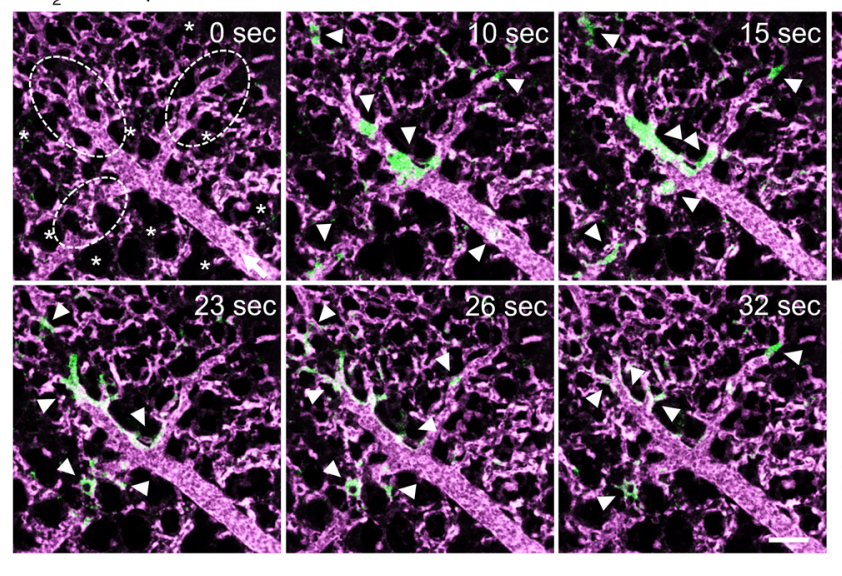

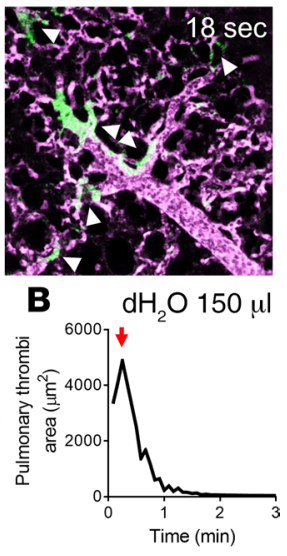

Figure 1. Intravascular hemolysis triggers acute pulmonary thrombosis in mice. WT mice were intravascularly (IV) administered with $150 \mu \mathrm{L} \mathrm{dH}_{2} \mathrm{O}$ ( $n=7$ mice) to induce acute hemolysis and pulmonary circulation was imaged using quantitative fluorescence intravital lung microscopy (qFILM). (A) qFILM images of the same field of view (FOV) at 7 different time points are shown. $\mathrm{t}=\mathrm{O}$ seconds $(\mathrm{s})$ corresponds to time point before $\mathrm{IV} \mathrm{dH}_{2} \mathrm{O}$ administration and other displayed time points are relative to $\mathrm{IV} \mathrm{dH}_{2} \mathrm{O}$. Pulmonary thrombosis was absent at $\mathrm{t}=\mathrm{O} \mathrm{s}$. Following $150 \mu \mathrm{L} \mathrm{dH}_{2} \mathrm{O}$, platelet-rich thrombi (white arrowheads) sequestered in the pulmonary arteriole $(t=10 \mathrm{~s})$. By $t=15 \mathrm{~s}$, the thrombi were trapped in the arteriolar bottlenecks causing local impairments in blood flow. Pulmonary thrombosis started to resolve by $\mathrm{t}=23 \mathrm{~s}$ and completely resolved by $\mathrm{t}=2$ minutes. Data are representative of 7 independent experiments. Platelets are shown in green and pulmonary microcirculation in purple. Asterisks denote alveoli. Dotted ellipses denote arteriolar bottlenecks. White arrow mark the direction of blood flow within the feeding arteriole. The diameter of the shown arteriole is $29 \mu \mathrm{m}$. Scale bar: $50 \mu \mathrm{m}$. Complete qFILM time series corresponding to $\mathbf{A}$ is shown in Supplemental Video 2. (B) Pulmonary thrombi area plotted as a function of time showing changes in the total area of platelet-rich thrombi

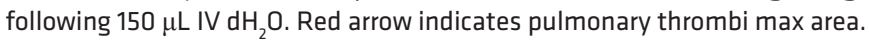

ole thrombosis in mice. This difference in the pathophysiology of acute hemolysis versus intravascular thrombin-induced pulmonary thrombosis suggests that thrombin generation most likely does not play a significant role in the pathogenesis of acute hemolysis-triggered pulmonary thrombosis.

Acute hemolysis-induced pulmonary thrombosis is likely to be ADP dependent. Intravascular hemolysis is also known to promote the release of ADP from erythrocytes (46-48), which can bind to $\mathrm{P}_{2} \mathrm{Y}_{1}$ and $\mathrm{P} 2 \mathrm{Y}_{12}$ purinergic receptors on platelets to trigger platelet activation and subsequent aggregation $(49,50)$. Therefore, we next compared the pathophysiology of pulmonary thrombosis triggered by acute hemolysis to the one by intravascular administration of ADP. Similar to acute hemolysis (Figure 1), intravascular ADP led to the development of transient pulmonary thrombosis in mice in a dose-dependent manner (Figure 5). Mice treated with $0.5 \mathrm{mg} / \mathrm{kg}$ intravascular ADP manifested mild pulmonary thrombosis (Supplemental Figure 3 and Supplemental Video 8), while intravascular administration of $2.5 \mathrm{mg} / \mathrm{kg}$ ADP led to the development of medium (500-1000 $\left.\mu \mathrm{m}^{2}\right)$ and large $\left(>1000 \mu \mathrm{m}^{2}\right)$ platelet-rich thrombi (green fluorescence) in the pulmonary arterioles (Figure 5A and Supplemental Video 9). Identical to acute hemolysis-induced pulmonary thrombosis (Figure 1), intravascular ADP-induced thrombi were initially unable to pass through the arteriolar bottlenecks, causing transient obstruction of the blood flow. As shown in Supplemental Video 9, the occlusion of arteriolar bottlenecks by platelet-rich thrombi resulted in transient ischemia, evident by the gradual loss of the vascular dye (purple fluorescence) in the capillaries downstream of occluded arteriole, followed by resolution of pulmonary thrombosis and complete recovery of blood flow (rescue of purple fluorescence) within 5 minutes after intravascular ADP. The total pulmonary thrombi area (Figure 5B), mean pulmonary thrombi maximum area (Figure 5C), and AUC (Figure 5D) were significantly larger following administration of 2.5 compared with $0.5 \mathrm{mg} / \mathrm{kg}$ intravascular ADP. Identical to the effect of eptifibatide on hemolysis-induced pulmonary thrombosis (Figure 2), $10 \mathrm{mg} / \mathrm{kg}$ intravascular eptifibatide completely abrogated ADP-induced pulmonary thrombosis in mice (Figure 6). In contrast, heparin, a potent anticoagulant (51), was ineffective in preventing intravascular ADP-induced transient pulmonary thrombosis in mice (Supplemental Figure 4, A and B, Supplemental Video 10). Both the mean pulmonary thrombi maximum area and the AUC were significantly attenuated by eptifibatide (Figure 6, B-D), but not heparin (Supplemental Figure 4, B-D), in mice intravascularly administered ADP. As shown in Supplemental Figure 5, 
A IV Eptifibatide $(10 \mathrm{mg} / \mathrm{kg})$ IV Fluorescent Abs \& Vessel Dye and
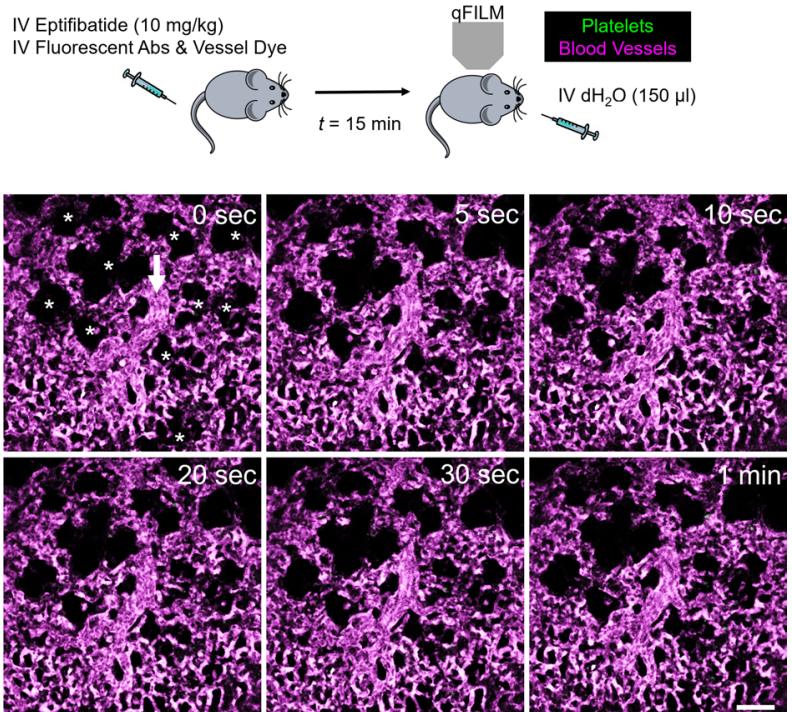

$\mathbf{B}$
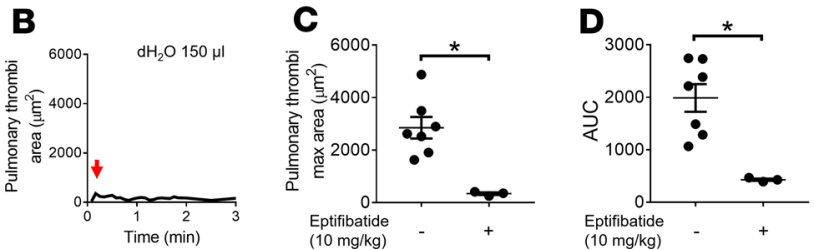

Figure 2. Acute hemolysis-induced pulmonary thrombosis is $\boldsymbol{\alpha l l b} \boldsymbol{\beta} 3$-dependent. (A) WT mice were intravascularly (IV)

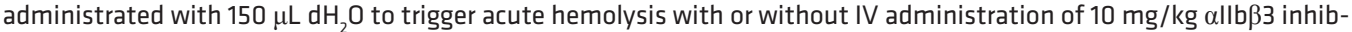
itor (eptifibatide) 15 minutes before IV $\mathrm{dH}_{2} \mathrm{O}$. Pulmonary circulation was imaged using quantitative fluorescence intravital lung microscopy (qFILM). qFILM images of the same field of view (FOV) at 6 different time points are shown to

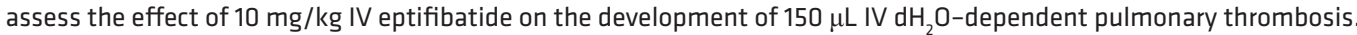
$\mathrm{t}=\mathrm{O}$ seconds ( $\mathrm{s}$ ) corresponds to time point before and $\mathrm{t}>\mathrm{O}$ s correspond to time points immediately following IV dH $\mathrm{O}$ administration. Pulmonary thrombosis was absent at $\mathrm{t}=\mathrm{O} \mathrm{s} \cdot \mathrm{dH}_{2} \mathrm{O}$ failed to evoke pulmonary thrombosis in mouse pretreated with eptifibatide. Platelets (green) and pulmonary microcirculation (purple). Asterisks denote alveoli. White arrow marks the direction of blood flow within the feeding arteriole. The diameter of the shown arteriole is $30 \mu \mathrm{m}$. Scale bar: $50 \mu \mathrm{m}$. Also refer to Supplemental Video 3. (B) Pulmonary thrombi area plotted as a function of time for the FOV shown in A. Red arrow indicates pulmonary thrombi maximum area. (C and D) Pulmonary thrombi max area and AUC in mice with ( $n=3$ mice) or without ( $n=7$ mice) pretreatment with $10 \mathrm{mg} / \mathrm{kg}$ IV eptifibatide before $150 \mu \mathrm{L}$ IV $\mathrm{dH} \mathrm{H}_{2} \mathrm{O}$ Pulmonary thrombi max area and AUC were estimated as described in Methods. Pulmonary thrombi max area and AUC were compared using Wilcoxon-Mann-Whitney test. Data are shown as mean \pm SEM. ${ }^{*} P<0.05$ when comparing with and without $10 \mathrm{mg} / \mathrm{kg}$ IV eptifibatide pretreatment.

the pulmonary thrombi maximum area was not significantly different between intravascular $\mathrm{dH}_{2} \mathrm{O}$ and 0.5 $\mathrm{mg} / \mathrm{kg}$ intravascular ADP-challenged mice. The similarities in the pathophysiology of acute hemolysis and intravascular ADP-induced pulmonary thrombosis suggest that ADP released from lysed erythrocytes most likely plays a major role in the pathogenesis of acute hemolysis-triggered pulmonary thrombosis.

ADP activates platelet $P 2 Y_{12}$ receptor to promote hemolysis-induced pulmonary thrombosis. Next, we tested whether inhibiting ADP-dependent platelet activation prevents acute hemolysis-induced pulmonary thrombosis in mice. Prasugrel is a thienopyridine class of drug, which is used clinically to treat patients with acute coronary syndrome who are undergoing percutaneous coronary intervention $(52,53)$. When taken orally, the active metabolite of prasugrel acts as a selective, irreversible, and potent platelet $\mathrm{P} 2 \mathrm{Y}_{12}$ receptor antagonist and prevents ADP-dependent platelet activation (54). We pretreated mice with 3 or $10 \mathrm{mg} / \mathrm{kg}$ prasugrel by oral gavage (PO) for 2 days and before inducing acute intravascular hemolysis by intravascular administering $\mathrm{dH}_{2} \mathrm{O}$. Remarkably, prasugrel pretreatment inhibited acute hemolysis-induced pulmonary arteriole thrombosis in a dose-dependent manner (Figure 7 and Supplemental Figure 6). Prasugrel inhibited both the formation and subsequent sequestration of platelet-rich thrombi in the pulmonary arterioles (Figure 7, A and B; Supplemental Figure 6, A and B; and Supplemental Videos 11 and 12). The pulmonary thrombi maximum area (Figure 7, B and C, and Supplemental Figure 6, B and C) and AUC 
A Thrombin $250 \mathrm{U} / \mathrm{kg}$

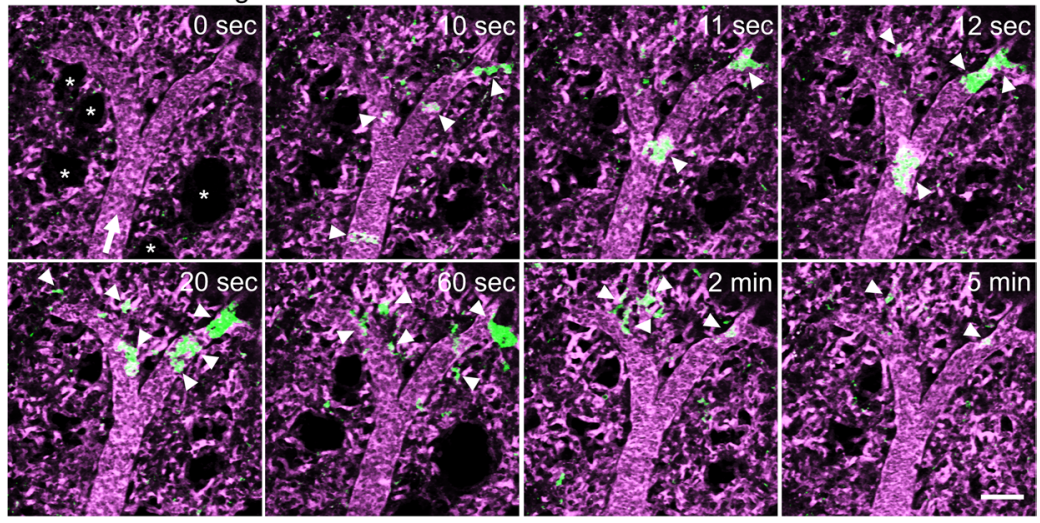

B Thrombin $500 \mathrm{U} / \mathrm{kg}$
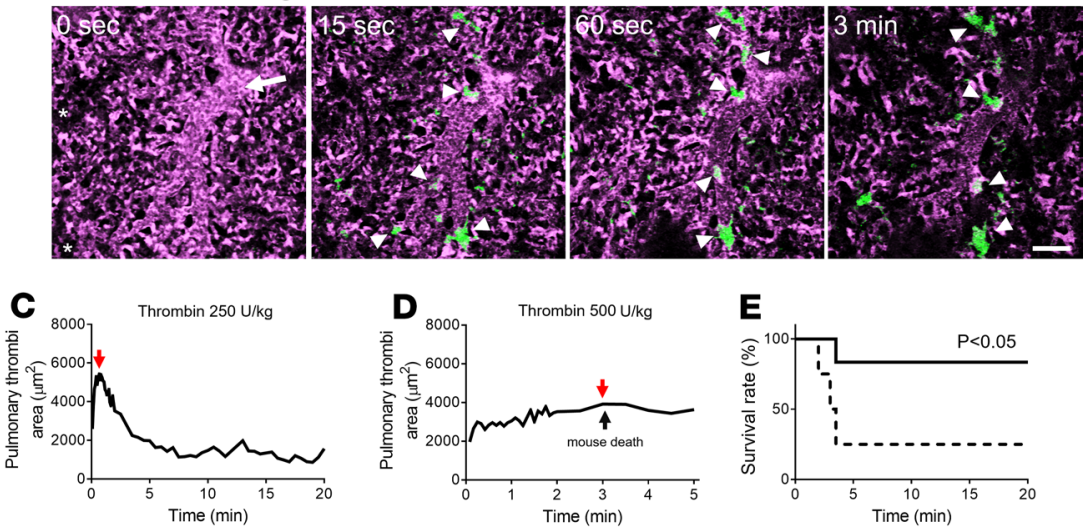

- Thrombin $250 \mathrm{U} / \mathrm{kg}(\mathrm{n}=5)$ --.-. Thrombin $500 \mathrm{U} / \mathrm{kg}(\mathrm{n}=4)$
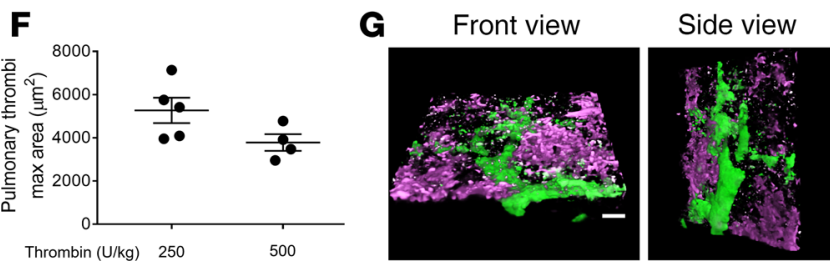

Back view

Figure 3. Thrombin triggers protracted and lethal pulmonary thrombosis in mice. WT mice were administered IV with $250 \mathrm{U} / \mathrm{kg}$ ( $n=5$ mice) or $500 \mathrm{U} / \mathrm{kg}$ ( $n=4$ mice) thrombin, and pulmonary circulation was imaged using qFILM. (A and B) qFILM images of the same FOV at different time points are shown. $t=0$ seconds (s) corresponds to time point before and $\mathrm{t}>\mathrm{O} \mathrm{s}$ correspond to time points following IV thrombin administration. Pulmonary thrombosis was absent at $\mathrm{t}=0 \mathrm{~s}$. Platelets are shown in green and pulmonary microcirculation in purple. (A) Following $250 \mathrm{U} / \mathrm{kg} \mathrm{IV} \mathrm{thrombin,}$ small $\left(<500 \mu \mathrm{m}^{2}\right)$ and medium (500-1000 $\left.\mu \mathrm{m}^{2}\right)$ platelet-rich thrombi (white arrowheads) sequestered in the pulmonary arteriole ( $\mathrm{t}=10-12 \mathrm{~s})$ and obstructed blood flow $(\mathrm{t}=20 \mathrm{~s})$. (B) Following $500 \mathrm{U} / \mathrm{kg}$ IV thrombin, small $\left(<500 \mu \mathrm{m}^{2}\right)$ and medium (500-1000 $\mu \mathrm{m}^{2}$ ) platelet-rich thrombi (white arrowheads) sequestered in the pulmonary arteriole to occlude the arteriolar bottlenecks. The mouse died by $\mathrm{t}=3$ minutes, leading to arrest of pulmonary blood flow, which was evident by the reduced intensity of vascular dye (purple fluorescence) and stationary erythrocytes (Supplemental Video 5). Asterisks denote alveoli. White arrow mark the direction of blood flow. The diameters of the arterioles shown in $\mathbf{A}$ and B are $39 \mu \mathrm{m}$ and $44 \mu \mathrm{m}$, respectively. Complete qFILM time series corresponding to $\mathbf{A}$ and $\mathbf{B}$ are shown in Supplemental Videos 4 and 5, respectively. (C and D) Pulmonary thrombi area plotted as a function of time following $250 \mathrm{U} / \mathrm{kg}$ (C) and $500 \mathrm{U} / \mathrm{kg}$ (D) IV thrombin within FOVs shown in $\mathbf{A}$ and $\mathbf{B}$, respectively. Red and black arrows indicate pulmonary thrombi maximum area values and the time of mouse death following $500 \mathrm{U} / \mathrm{kg}$ IV thrombin, respectively. (E) Survival rate during qFILM experiments in WT mice IV administered with either $250 \mathrm{U} / \mathrm{kg}(n=5$ mice $)$ or $500 \mathrm{U} / \mathrm{kg}(n=4)$ thrombin $(P=0.046$, log-rank test). (F) Pulmonary thrombi max areas in mice following $250 \mathrm{U} / \mathrm{kg}(n=5$ mice) and $500 \mathrm{U} / \mathrm{kg}$ ( $n$ $=4$ mice) IV thrombin. Pulmonary thrombi max areas were compared using Wilcoxon-Mann-Whitney test. Data are shown as mean \pm SEM. (G) Three-dimensional qFILM image of a lethal pulmonary thrombosis developed within a large pulmonary arteriole $(57 \mu \mathrm{m})$ of a mouse administered with $500 \mathrm{U} / \mathrm{kg}$ IV thrombin. Platelets (green) and pulmonary microcirculation (purple). Refer to Supplemental Video 6. Scale bar: $50 \mu \mathrm{m}$. 
A IV Eptifibatide $(10 \mathrm{mg} / \mathrm{kg})$ IV Fluorescent Abs \& Vessel Dye

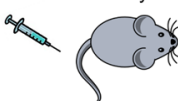
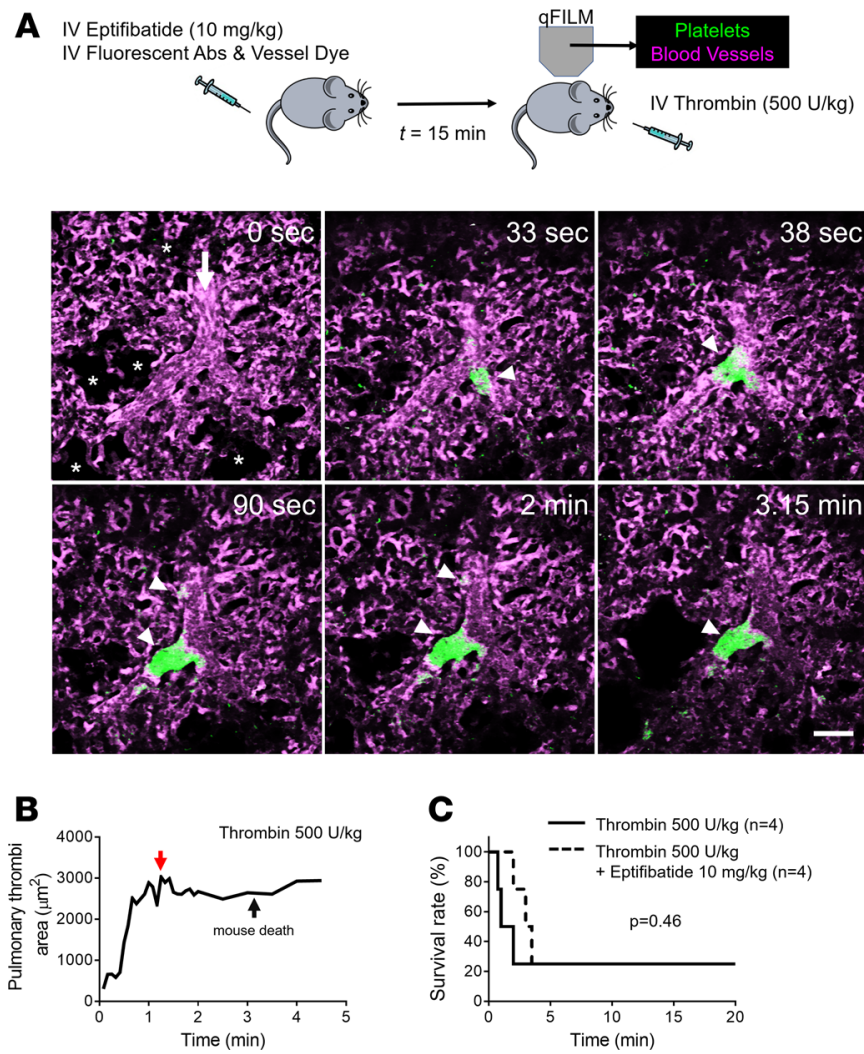

Figure 4. Thrombin-triggered lethal pulmonary thrombosis is platelet- $\alpha$ llb $\beta 3$ independent. (A) WT mice were intravascularly (IV) administered $500 \mathrm{U} / \mathrm{kg}$ thrombin with or without IV administration of $10 \mathrm{mg} / \mathrm{kg} \alpha$ llb $\beta 3$ inhibitor (eptifibatide) 15 minutes before IV thrombin. Pulmonary circulation was imaged using quantitative fluorescence intravital lung microscopy (qFILM). qFILM images of the same field of view (FOV) at 6 different time points are shown to assess the effect of 10 $\mathrm{mg} / \mathrm{kg}$ IV eptifibatide on the development of $500 \mathrm{U} / \mathrm{kg}$ IV thrombin-dependent pulmonary thrombosis. $\mathrm{t}=0$ seconds (s) corresponds to time point before and $\mathrm{t}>0 \mathrm{~s}$ correspond to time points immediately following IV thrombin administration. Pulmonary thrombosis was absent at $\mathrm{t}=0 \mathrm{~s}$. Following $500 \mathrm{U} / \mathrm{kg}$ IV thrombin, medium $\left(500-1000 \mu \mathrm{m}^{2}\right)$ and large $(>1000$ $\mu \mathrm{m}^{2}$ ) platelet-rich thrombi (white arrowheads) sequestered in the pulmonary arteriole and traveled down the pulmonary arterioles to occlude the arteriolar bottlenecks $(t=90 \mathrm{~s})$. The mouse died at $t=3.15$ minutes, leading to arrest of pulmonary blood flow, which was evident by the presence of stationary erythrocytes (Supplemental Video 7) and decrease in vascular dye (purple fluorescence) in the FOV. Platelets (green) and pulmonary microcirculation (purple). Asterisks denote the alveoli. White arrow mark the direction of blood flow. The diameter of the arteriole is $33 \mu \mathrm{m}$. Scale bar: $50 \mu \mathrm{m}$. See also Supplemental Video 7 for the complete qFILM time series. (B) Pulmonary thrombi area plotted as a function of time for the FOV shown in A. Red and black arrows indicate pulmonary thrombi maximum area and the time of mouse death, respectively. (C) Survival rate during qFILM experiments in WT mice pretreated ( $n=4$ mice) or untreated ( $n=4$ mice) with $10 \mathrm{mg} / \mathrm{kg}$ IV eptifibatide before $500 \mathrm{U} / \mathrm{kg}$ IV thrombin $(P=0.46$, log-rank test)

(Figure 7D) were significantly attenuated in mice treated with prasugrel before intravascular $\mathrm{dH}_{2} \mathrm{O}$. As shown in Supplemental Videos 11 and 12, mice pretreated with prasugrel before intravascular $\mathrm{dH}_{2} \mathrm{O}$ did not develop medium and large platelet-rich thrombi $\left(>500 \mu \mathrm{m}^{2}\right)$ observed in intravascular $\mathrm{dH}_{2} \mathrm{O}$-administered mice (Figure 1 and Supplemental Video 2). Although small platelet-rich thrombi $\left(<500 \mu \mathrm{m}^{2}\right)$ were still observed in the pulmonary arterioles of prasugrel treated mice, these thrombi were too small to obstruct the pulmonary blood flow (Figure 7A; Supplemental Figure 6A; and Supplemental Videos 11 and 12). These findings suggest that ADP-dependent platelet $\mathrm{P}_{2} \mathrm{Y}_{12}$ signaling plays a major role in acute hemolysisinduced pulmonary arteriole thrombosis.

\section{Discussion}

Epidemiological evidence suggests that in situ pulmonary thrombosis is a major pathological event contributing to cardiopulmonary morbidities associated with hemolytic disorders; however, the molecular, cellular, and biophysical mechanisms of hemolysis-induced pulmonary thrombosis remain incompletely understood $(19,20,35,36)$. To address this, we have used intravital microscopy to study the kinetics of pulmonary throm- 
A ADP $2.5 \mathrm{mg} / \mathrm{kg}$
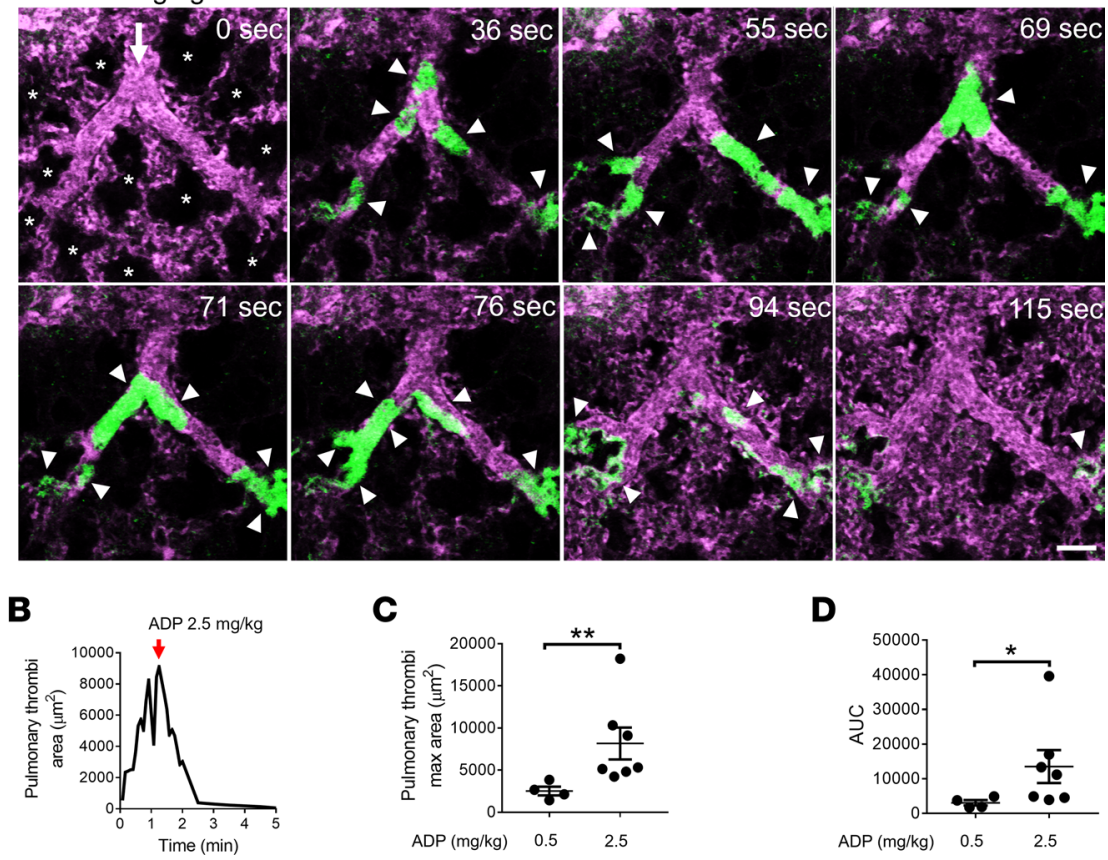

Figure 5. ADP triggers reversible acute pulmonary thrombosis in mice. WT mice were IV administered either 0.5 $\mathrm{mg} / \mathrm{kg} \operatorname{ADP}$ ( $n=4$ mice) or $2.5 \mathrm{mg} / \mathrm{kg} \operatorname{ADP}(n=7$ mice), and pulmonary circulation was imaged using qFILM. (A) qFILM images of the same field of view (FOV) at 8 different time points are shown. $t=0$ seconds (s) corresponds to time point before IV ADP administration, and other displayed time points are relative to IV ADP. Pulmonary thrombosis was absent at $\mathrm{t}=0 \mathrm{~s}$. Following $2.5 \mathrm{mg} / \mathrm{kg}$ IV ADP, medium $\left(500-1000 \mu \mathrm{m}^{2}\right)$ and large size $\left(>1000 \mu \mathrm{m}^{2}\right)$ platelet-rich thrombi (white arrowheads) sequestered in the pulmonary arteriole $(t=36 \mathrm{~s})$. The thrombi obstructed the arteriolar bottlenecks $(t=55 \mathrm{~s})$, resulting in loss of the pulmonary blood flow, which was evident by the absence of the vascular dye (purple fluorescence) in the capillaries downstream of the embolized arteriole. Pulmonary thrombosis resolved and the capillary blood flow recovered (purple fluorescence was back) by $t=115 \mathrm{~s}$. Platelets (green) and pulmonary microcirculation (purple). Asterisks denote alveoli. White arrows mark the direction of blood flow. The diameters of the arteriole is $41 \mu \mathrm{m}$. Scale bar: $50 \mu \mathrm{m}$. Complete qFILM time series corresponding to $\mathbf{A}$ is shown in Supplemental Video 9. (B) Pulmonary thrombi area plotted as a function of time to show changes in the total area of platelet-rich thrombi following $2.5 \mathrm{mg} / \mathrm{kg}$ IV ADP within FOV shown in A. Pulmonary thrombi maximum area value marked by red arrow. (C and $\mathbf{D})$ Pulmonary thrombi max area and AUC were estimated to compare pulmonary thrombosis development in mice following $0.5 \mathrm{mg} / \mathrm{kg}$ IV ADP ( $n=4$ mice) and $2.5 \mathrm{mg} / \mathrm{kg}$ IV ADP ( $n=7$ mice). Pulmonary thrombi max area and AUC were compared using Wilcoxon-Mann-Whitney test. Data are shown as mean \pm SEM. ${ }^{*} P<0.05,{ }^{* *} P<0.01$ for $0.5 \mathrm{mg} / \mathrm{kg}$ vs. $2.5 \mathrm{mg} / \mathrm{kg}$ IV ADP.

bosis progression in mice, following acute intravascular hemolysis (intravascular $\mathrm{dH}_{2} \mathrm{O}$ ). Acute hemolysis led to transient pulmonary thrombosis in mice in vivo, which was caused by the development of platelet-rich thrombi in the precapillary pulmonary arterioles, leading to impairment of pulmonary blood flow.

We found that acute intravascular hemolysis led to transient nonlethal pulmonary arteriole thrombosis in mice, which was dependent on $\alpha \operatorname{IIb} \beta 3$-mediated platelet aggregation. Previous studies suggest that ADP released from lysed erythrocytes may play a role in platelet activation $(47,55)$. Although ADP is known to activate platelet-purinergic receptors $\mathrm{P} 2 \mathrm{Y}_{1}$ and $\mathrm{P} 2 \mathrm{Y}_{12}$ to induce platelet shape change, degranulation and reversible aggregation in vitro (56) - a role for ADP-dependent purinergic signaling in hemolysis-induced pulmonary thrombosis in vivo - has never been reported. We show for the first time to our knowledge that pulmonary thrombosis triggered by acute hemolysis shares pathogenesis with ADP but not thrombin-triggered pulmonary thrombosis in mice in vivo. We also show that acute hemolysis-induced pulmonary thrombosis is abolished following the inhibition of platelet $\mathrm{P} 2 \mathrm{Y}_{12}$ receptor signaling. Taken together, these findings suggest that ADP released during acute hemolysis activates purinergic signaling in platelets to promote $\alpha \operatorname{Ilb} \beta 3$-dependent acute reversible pulmonary arteriole thrombosis.

Our current study has a few limitations that need to be addressed in future investigations. First, the current study investigates the mechanism of pulmonary thrombosis secondary to acute intravascular hemolysis. Importantly, low-grade chronic hemolysis also occurs in several hemolytic disorders $(1,5,8,10,15)$ and could 
A IV Eptifibatide $(10 \mathrm{mg} / \mathrm{kg})$ IV Fluorescent Abs \& Vessel Dye
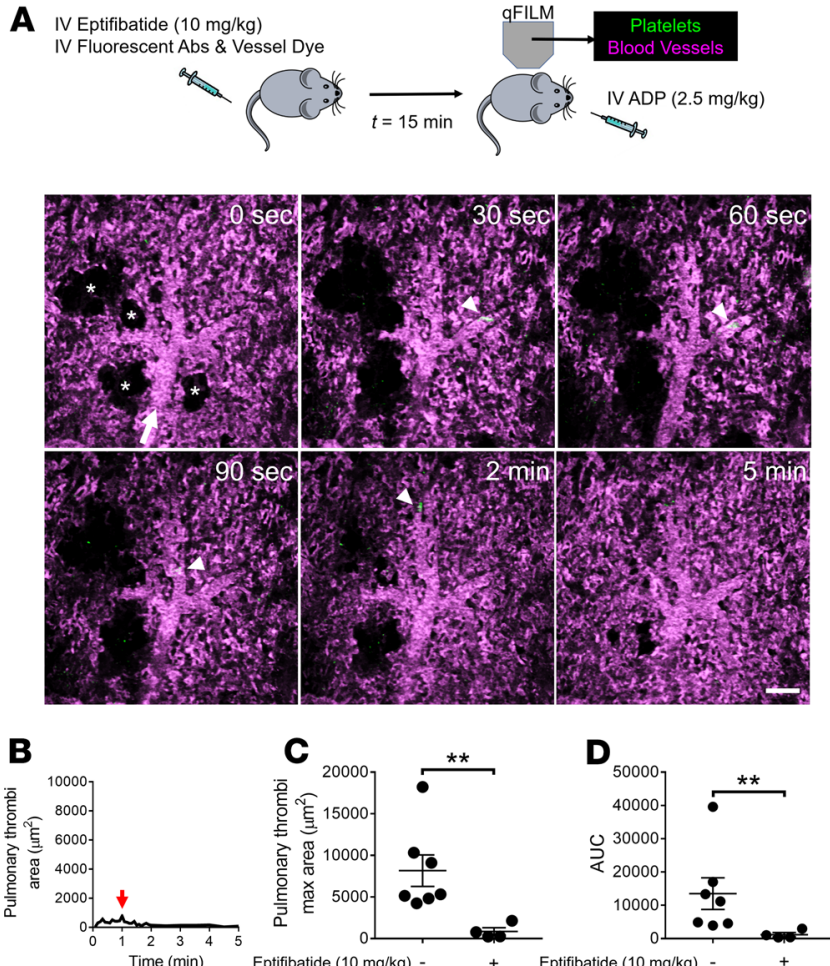

Figure 6. ADP-induced pulmonary thrombosis in mice is $\boldsymbol{\alpha}$ llb $\beta 3$ dependent. (A) WT mice were IV administered 2.5 $\mathrm{mg} / \mathrm{kg}$ ADP with or without IV administration of $10 \mathrm{mg} / \mathrm{kg} \alpha \mathrm{llb} \beta 3$ inhibitor (eptifibatide) 15 minutes before IV ADP. Pulmonary circulation was imaged using quantitative fluorescence intravital lung microscopy (qFILM). qFILM images of the same field of view (FOV) at 6 different time points are shown to assess the effect of eptifibatide on the development of IV ADP-dependent pulmonary thrombosis. $t=0$ seconds (s) corresponds to time point before and $t>0$ s correspond to time points immediately following IV ADP administration. Pulmonary thrombosis was absent at $t=0$ s. ADP failed to evoke pulmonary thrombosis in mouse pretreated with eptifibatide. Platelets (green) and pulmonary microcirculation (purple). Asterisks denote alveoli. White arrow mark the direction of blood flow within the arterioles. The diameter of the arteriole shown is $38 \mu \mathrm{m}$. Scale bar: $50 \mu \mathrm{m}$. (B) Pulmonary thrombi area plotted as a function of time for the FOV shown in A. Red arrow indicates pulmonary thrombi maximum area. (C and D) Pulmonary thrombi max area and AUC in mice with ( $n=4$ mice) or without ( $n=7$ mice) pretreatment with eptifibatide before IV ADP. Pulmonary thrombi max area and AUC were estimated as described in Methods. Pulmonary thrombi max area and AUC were compared using Wilcoxon-Mann-Whitney test. Data are shown as mean \pm SEM. ${ }^{* *} P<0.01$ when comparing with and without eptifibatide pretreatment.

possibly have additional implications on pulmonary thrombosis that did not manifest in our acute hemolysis model. Second, anionic phospholipids exposed on lysed-erythrocyte membrane fragments also promote coagulation and, therefore, may contribute to hemolysis-induced pulmonary thrombosis $(1,42)$. Third, von Willebrand factor (VWF) released by injured endothelium may also contribute to pulmonary thrombosis by promoting platelet adhesion and activation (57). Indeed, platelet interaction with VWF has been shown to play a crucial role in the pathophysiology of multiple hemolytic disorders including TTP $(7,8,20,58)$. Fourth, nitric oxide (NO) depletion and ROS generation by cell-free hemoglobin may also contribute to hemolysis-induced platelet activation and pulmonary thrombosis $(3,17,27,55)$. Fifth, although thrombin did not seem to play a direct role in our study, thrombin generation may still contribute to acute hemolysis-triggered pulmonary thrombosis by unknown mechanisms. Sixth, changes in the vascular tone caused by thrombin or adenosine generated during hemolysis may regulate the pathogenesis of acute hemolysis-induced pulmonary thrombosis. Notwithstanding these limitations, the current study is the first to our knowledge to use intravital lung microscopy in live mice to reveal that platelet-purinergic signaling promotes platelet-dependent pulmonary arteriole thrombosis associated with acute intravascular hemolysis.

\section{Methods}

Reagents, animals, and surgical preparation. WT C57BL/6J mice (8-12 weeks old) were purchased from the Jackson Laboratory. See Supplemental Methods for details on used reagents and mouse surgical preparation. 
A

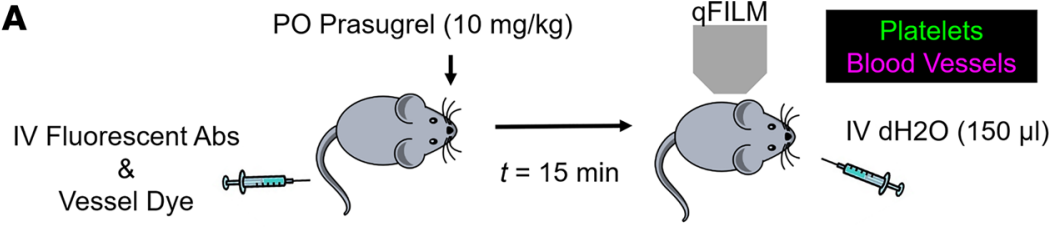

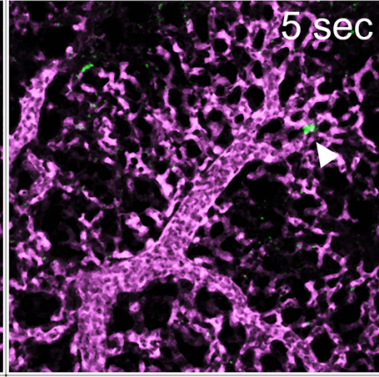
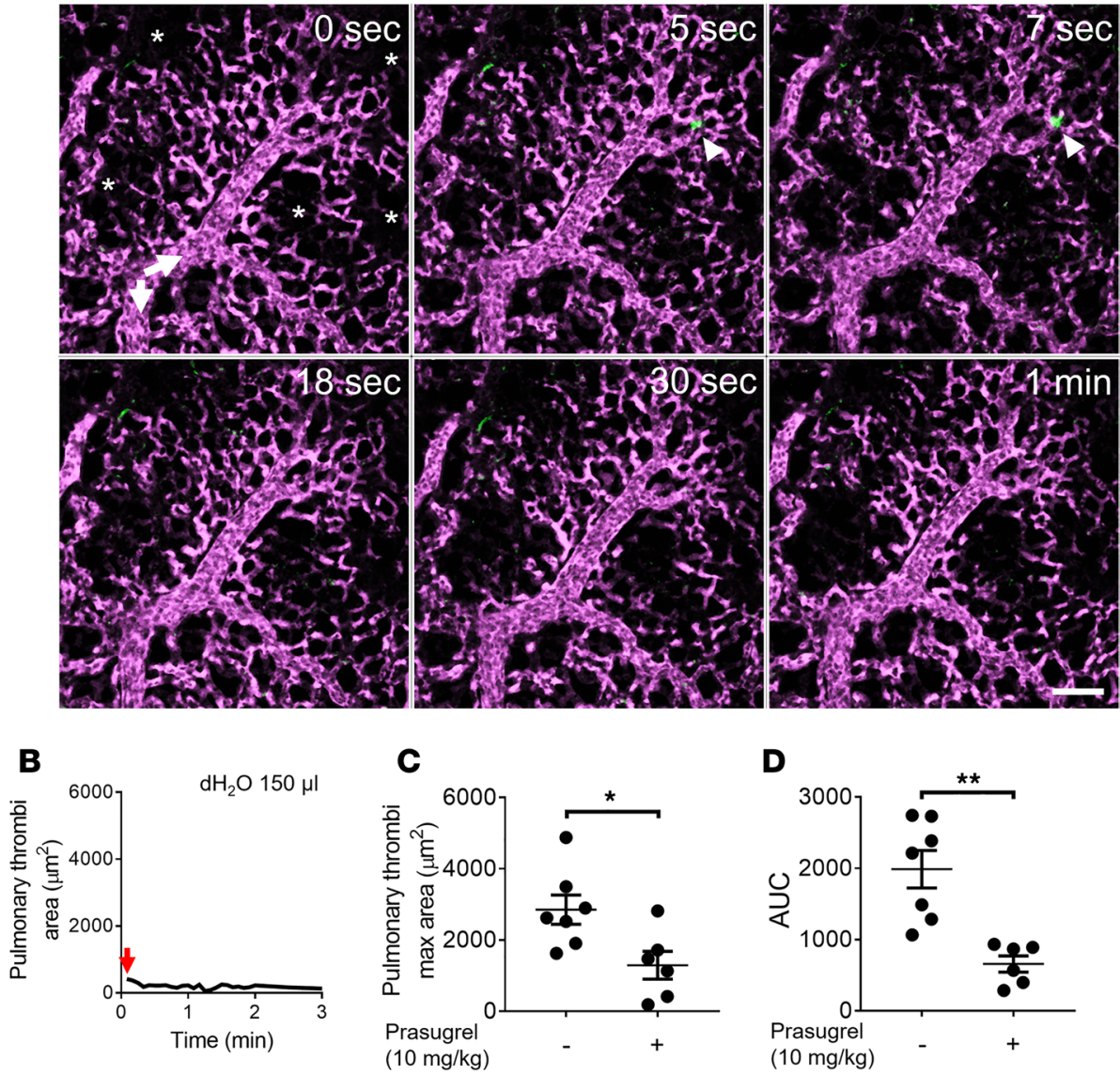

Figure 7. Inhibition of platelet $\mathbf{P 2 Y _ { 1 2 }}$ receptor abrogates hemolysis-induced pulmonary thrombosis in mice. (A)

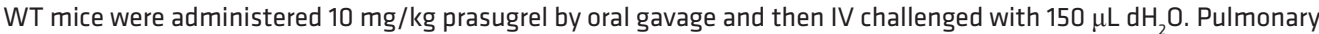
circulation was imaged using quantitative fluorescence intravital lung microscopy (qFILM). qFILM images of the same field of view (FOV) at 6 different time points are shown. $t=0$ seconds (s) corresponds to time point before and $t>0$ $\mathrm{s}$ correspond to time points immediately following $\mathrm{IV} \mathrm{dH}_{2} \mathrm{O}$ administration. Pulmonary thrombosis was absent at $\mathrm{t}=$ $\mathrm{O}$ s. $\mathrm{dH}_{2} \mathrm{O}$ failed to evoke pulmonary thrombosis in mouse pretreated with prasugrel. Platelets (green) and pulmonary microcirculation (purple). Asterisks denote alveoli. White arrows mark the direction of blood flow within the feeding arterioles. The diameter of the arteriole shown is $30 \mu \mathrm{m}$. Scale bar: $50 \mu \mathrm{m}$. Also refer to Supplemental Video 11. (B) Pulmonary thrombi area plotted as a function of time for the FOV shown in $\mathbf{A}$. Red arrow indicates pulmonary thrombi maximum area. (C and D) Pulmonary thrombi max area and AUC in mice with ( $n=6$ mice) or without ( $n=7$ mice) pretreatment with prasugrel before IV $\mathrm{dH}_{2} \mathrm{O}$. Pulmonary thrombi max area and AUC were estimated as described in Methods. Pulmonary thrombi max area and AUC were compared using Wilcoxon-Mann-Whitney test. Data are shown as mean $\pm \mathrm{SEM} .{ }^{*} P<0.05,{ }^{*} P<0.01$ when comparing with and without prasugrel pretreatment.

qFILM of pulmonary thrombosis. The current study is an adaptation of qFILM approach used previously (59-63). qFILM of the mouse pulmonary microcirculation was performed using a Nikon A1R Multi-Photon-Excitation (MPE) Ni-E upright motorized microscope (Nikon Instruments). Two-dimensional time series of qFILM images were acquired with NIS-Elements software using a prechirped Chameleon Laser Vision (Coherent) emitting an excitation wavelength of $850 \mathrm{~nm}$, an APO LWD 25× water immersion objective with 1.1 NA, a high-speed resonant scanning mode capable of acquisition at $512 \times 512$ resolution with $2 \times$ line averaging and bidirectional scanning ( 15 frames per second), and 4 GaAsP NDD detectors. The 4 detectors collected fluorescent light transmitted through $450 / 20$ 
nm (detector 1; blue channel), 525/50 nm (detector 2; green channel), 576/26 nm (detector 3; red channel), and 685/70 nm (detector 4; far red channel) band pass filters. In this study, we used detector 1 for V450 and detector 2 for FITC. The position of the microscope stage was selected in the $z$ and $x-y$ planes through a Nano-Drive (Mad City Labs Inc.) and a control pad (Prior Scientific Inc.), respectively. A single 2-dimensional plane (field of view [FOV] $\sim 512 \times 512$ pixel at $0.67 \mu \mathrm{m}$ per pixel resolution) in the $z$-direction was selected, and multiple images were acquired at a rate of 15 frames/second for each mouse. Hemolysis in mice was evoked by intravascular injection of $\mathrm{dH}_{2} \mathrm{O}(150 \mu \mathrm{L})$ through a catheter placed in carotid artery (37). Intravascular $\mathrm{dH}_{2} \mathrm{O}(150 \mu \mathrm{L})$ is known to trigger a physiologically relevant level of acute hemolysis in mice $(37,64,65)$. Pulmonary thrombosis was also induced in mice by intravascular administration of ADP or thrombin. Some mice were given intravascular heparin $(300 \mathrm{U} / \mathrm{kg})$ or eptifibatide $(10 \mathrm{mg} / \mathrm{kg}) 15$ minutes before initiation of pulmonary thrombosis $(66,67)$. Prasugrel was suspended in a $5 \%$ solution of gum arabic $(68)$ and administered once a day for 2 days and, additionally, approximately 4 hours before qFILM to each mouse by PO with a volume of $10 \mathrm{~mL} / \mathrm{kg}$. Physiological saline was intravascularly administered to mice as a vehicle in control experiments. FITC-dextran (75 $\mu \mathrm{g} /$ mouse) and Violet 450 (V450) rat-anti mouse CD49b mAb (BD Biosciences; clone DX5) (7 $\mathrm{g}$ /mouse) were intravascularly administered through the carotid artery catheter to enable in vivo visualization of the lung microcirculation and in vivo staining of platelets, respectively. Anti-CD49b mAb has been used widely for in vivo visualization of platelets $(60,69,70)$. In each mouse, a single FOV (FOV $\sim 118,000 \mu \mathrm{m}^{2}$ ) containing a pulmonary arteriole $(30-50 \mu \mathrm{m}$ diameter) and the downstream pulmonary capillary bed were randomly selected, and presence or absence of pulmonary thrombosis was assessed using qFILM. These assessments were conducted in 3-7 mice in each test group. The time series of qFILM images of pulmonary arteriolar microcirculation in each FOV were recorded prior ( $t=0$ seconds) and up to 30 minutes after intravascular administration of $\mathrm{dH}_{2} \mathrm{O}, \mathrm{ADP}$, or thrombin, followed by euthanization of mouse with an overdose of anesthesia.

qFILM image processing and data analysis. Refer to Supplemental Methods for details on qFILM image processing. Pulmonary arterioles and downstream capillaries were analyzed for the quantitative assessment of pulmonary thrombosis. Arterioles were identified as blood vessels draining blood into smaller daughter arterioles, followed by even smaller pulmonary capillaries. Platelet-rich pulmonary thrombi were defined as platelet aggregates (area $>10 \mu \mathrm{m}^{2}$ ) sequestered within the precapillary pulmonary arterioles and extending down into the pulmonary capillaries. Two-dimensional sizes (areas in $\mu \mathrm{m}^{2}$ ) of platelet-rich thrombi were estimated in NIS-Elements software (NIKON) by converting qFILM images into binary images and adjusting the threshold range of the intensity histograms uniformly over the entire FOV in each image frame of the time series (Supplemental Figure 7). The sizes of all the platelet-rich thrombi in a single image frame were added to generate total pulmonary thrombi area, which was plotted as a function of time in GraphPad Prism 7 (GraphPad Software). This approach allowed us to follow the kinetic of initiation and progression of pulmonary thrombosis in observed FOV. Changes in total pulmonary thrombi area over time served to calculate pulmonary thrombi maximum area and AUC. Pulmonary thrombi maximum area value reflects the maximum total area of platelet-rich thrombi in a FOV during the qFILM observation period. AUC is a combined measure of both size and lifetime of platelet-rich thrombi during the qFILM observation period. In some experiments, development of pulmonary thrombosis resulted in irreversible cessation of pulmonary blood flow, followed by mouse death. For such experiments, AUC was not estimated.

Statistics. Pulmonary thrombi max area and AUC were compared between groups using the Wilcoxon-Mann-Whitney test (when the data was not normally distributed) or the 2-tailed unpaired Student's $t$ test (when the data was normally distributed). Survival data were compared using Kaplan-Meier log-rank (Mantel-Cox) test. Data are shown as mean \pm SEM. $P$ value of less than 0.05 was used to determine significance.

Study approval. All animal experiments were approved by the IACUC of the University of Pittsburgh.

\section{Author contributions}

TB designed, performed, and analyzed the qFILM experiments and wrote the manuscript. RV, MFB, and SCW contributed to the qFILM experiments. ET was responsible for mouse colony management. MVR, MDN, and MTG were involved in experimental design and manuscript writing. PS was responsible for experimental design, manuscript writing, and project supervision. TB and PS wrote the manuscript with consultation and contribution from all coauthors. 


\section{Acknowledgments}

This study was supported by NHLBI 1R01HL128297-01 (PS), NHLBI 1R01 HL141080-01A1 (PS and MDN), 1R35GM119526-01 (MDN), American Heart Association 18TPA34170588 (PS), funds from the Hemophilia Center of Western Pennsylvania and Vitalant (PS), American Society of Hematology Postdoctoral Scholar Award (TB), and American Heart Association predoctoral fellowship 19PRE34430188 (RV). The Nikon multiphoton excitation microscope was funded by NIH grants 1S10RR028478-01 and S10OD025041 (SCW).

Address correspondence to: Prithu Sundd, Division of Pulmonary, Allergy and Critical Care Medicine, Principal Investigator-Heart, Lung and Blood Vascular Medicine Institute, University of Pittsburgh School of Medicine, BST E1255, 200 Lothrop Street, Pittsburgh, Pennsylvania 15261, USA. Phone: 412.648.9103; Email: prs51@pitt.edu.

1. Ataga KI, Cappellini MD, Rachmilewitz EA. Beta-thalassaemia and sickle cell anaemia as paradigms of hypercoagulability. $\mathrm{Br}$ J Haematol. 2007;139(1):3-13.

2. Ataga KI, Key NS. Hypercoagulability in sickle cell disease: new approaches to an old problem. Hematology Am Soc Hematol Educ Program. 2007;(1):91-96.

3. Brzoska T, Kato GJ, Sundd P. The Role of Platelets in Sickle Cell Disease. In: Michelson AD, ed. Platelets. Elsevier Inc.; 2019:563-580.

4. Eldor A, Rachmilewitz EA. The hypercoagulable state in thalassemia. Blood. 2002;99(1):36-43.

5. Van Bijnen ST, Van Heerde WL, Muus P. Mechanisms and clinical implications of thrombosis in paroxysmal nocturnal hemoglobinuria. J Thromb Haemost. 2012;10(1):1-10.

6. de Latour RP, et al. Paroxysmal nocturnal hemoglobinuria: natural history of disease subcategories. Blood. 2008;112(8):3099-3106.

7. George JN, Nester CM. Syndromes of thrombotic microangiopathy. N Engl J Med. 2014;371(7):654-666.

8. Joly BS, Coppo P, Veyradier A. Thrombotic thrombocytopenic purpura. Blood. 2017;129(21):2836-2846.

9. Chandler WL, et al. Prothrombotic coagulation abnormalities preceding the hemolytic-uremic syndrome. N Engl J Med. 2002;346(1):23-32.

10. Effenberger-Neidnicht K, Hartmann M. Mechanisms of Hemolysis During Sepsis. Inflammation. 2018;41(5):1569-1581.

11. Semeraro N, Ammollo CT, Semeraro F, Colucci M. Sepsis, thrombosis and organ dysfunction. Thromb Res. 2012;129(3):290-295.

12. Cunnington AJ, Njie M, Correa S, Takem EN, Riley EM, Walther M. Prolonged neutrophil dysfunction after Plasmodium falciparum malaria is related to hemolysis and heme oxygenase-1 induction. J Immunol. 2012;189(11):5336-5346.

13. Gladwin MT, Ofori-Acquah SF. Erythroid DAMPs drive inflammation in SCD. Blood. 2014;123(24):3689-3690.

14. Kato GJ, Steinberg MH, Gladwin MT. Intravascular hemolysis and the pathophysiology of sickle cell disease. J Clin Invest. 2017;127(3):750-760.

15. Ataga KI. Hypercoagulability and thrombotic complications in hemolytic anemias. Haematologica. 2009;94(11):1481-1484.

16. Rother RP, Bell L, Hillmen P, Gladwin MT. The clinical sequelae of intravascular hemolysis and extracellular plasma hemoglobin: a novel mechanism of human disease. JAMA. 2005;293(13):1653-1662.

17. Sundd P, Gladwin MT, Novelli EM. Pathophysiology of Sickle Cell Disease. Annu Rev Pathol. 2019;14:263-292.

18. Adedeji MO, Cespedes J, Allen K, Subramony C, Hughson MD. Pulmonary thrombotic arteriopathy in patients with sickle cell disease. Arch Pathol Lab Med. 2001;125(11):1436-1441.

19. Mekontso Dessap A, et al. Pulmonary artery thrombosis during acute chest syndrome in sickle cell disease. Am J Respir Crit Care Med. 2011;184(9):1022-1029.

20. Anea $\mathrm{CB}$, et al. Pulmonary platelet thrombi and vascular pathology in acute chest syndrome in patients with sickle cell disease. Am J Hematol. 2016;91(2):173-178.

21. Sonakul D, Pacharee P, Laohapand T, Fucharoen S, Wasi P. Pulmonary artery obstruction in thalassaemia. Southeast Asian J Trop Med Public Health. 1980;11(4):516-523.

22. Hill A, et al. Under-recognized complications in patients with paroxysmal nocturnal haemoglobinuria: raised pulmonary pressure and reduced right ventricular function. Br J Haematol. 2012;158(3):409-414.

23. Panoskaltsis N, Derman MP, Perillo I, Brennan JK. Thrombotic thrombocytopenic purpura in pulmonary-renal syndromes. $A m$ J Hematol. 2000;65(1):50-55.

24. Martinez AJ, Maltby JD, Hurst DJ. Thrombotic thrombocytopenic purpura seen as pulmonary hemorrhage. Arch Intern Med. 1983;143(9):1818-1820.

25. Upadhyaya K, Barwick K, Fishaut M, Kashgarian M, Siegel NJ. The importance of nonrenal involvement in hemolytic-uremic syndrome. Pediatrics. 1980;65(1):115-120.

26. Blaisdell FW. Pathophysiology of the respiratory distress syndrome. Arch Surg. 1974;108(1):44-49.

27. Villagra J, Shiva S, Hunter LA, Machado RF, Gladwin MT, Kato GJ. Platelet activation in patients with sickle disease, hemolysis-associated pulmonary hypertension, and nitric oxide scavenging by cell-free hemoglobin. Blood. 2007;110(6):2166-2172.

28. Polanowska-Grabowska R, et al. P-selectin-mediated platelet-neutrophil aggregate formation activates neutrophils in mouse and human sickle cell disease. Arterioscler Thromb Vasc Biol. 2010;30(12):2392-2399.

29. Eldor A, Lellouche F, Goldfarb A, Rachmilewitz EA, Maclouf J. In vivo platelet activation in beta-thalassemia major reflected by increased platelet-thromboxane urinary metabolites. Blood. 1991;77(8):1749-1753.

30. Ruf A, et al. In-vivo platelet activation correlates with red cell anionic phospholipid exposure in patients with beta-thalassaemia major. Br J Haematol. 1997;98(1):51-56. 
31. Wiedmer T, Hall SE, Ortel TL, Kane WH, Rosse WF, Sims PJ. Complement-induced vesiculation and exposure of membrane prothrombinase sites in platelets of paroxysmal nocturnal hemoglobinuria. Blood. 1993;82(4):1192-1196.

32. Karpman D, Manea M, Vaziri-Sani F, Ståhl AL, Kristoffersson AC. Platelet activation in hemolytic uremic syndrome. Semin Thromb Hemost. 2006;32(2):128-145.

33. Chaturvedi S, Ghafuri DL, Glassberg J, Kassim AA, Rodeghier M, DeBaun MR. Rapidly progressive acute chest syndrome in individuals with sickle cell anemia: a distinct acute chest syndrome phenotype. Am J Hematol. 2016;91(12):1185-1190.

34. Alhandalous $\mathrm{CH}$, et al. Platelets decline during Vaso-occlusive crisis as a predictor of acute chest syndrome in sickle cell disease. Am J Hematol. 2015;90(12):E228-E229.

35. Sumiyoshi A, Thakerngpol K, Sonakul D. Pulmonary microthromboemboli in thalassemic cases. Southeast Asian J Trop Med Public Health. 1992;23 Suppl 2:29-31.

36. Nokes T, George JN, Vesely SK, Awab A. Pulmonary involvement in patients with thrombotic thrombocytopenic purpura. Eur J Haematol. 2014;92(2):156-163.

37. Almeida $\mathrm{CB}$, et al. Acute hemolytic vascular inflammatory processes are prevented by nitric oxide replacement or a single dose of hydroxyurea. Blood. 2015;126(6):711-720.

38. O'Shea JC, Tcheng JE. Eptifibatide: a potent inhibitor of the platelet receptor integrin glycoprotein IIb/IIIa. Expert Opin Pharmacother. 2002;3(8):1199-1210.

39. Hoffman M, Monroe DM. A cell-based model of hemostasis. Thromb Haemost. 2001;85(6):958-965.

40. Wolberg AS, et al. Venous thrombosis. Nat Rev Dis Primers. 2015;1:15006.

41. Peters M, Plaat BE, ten Cate H, Wolters HJ, Weening RS, Brandjes DP. Enhanced thrombin generation in children with sickle cell disease. Thromb Haemost. 1994;71(2):169-172.

42. Tomer A, Harker LA, Kasey S, Eckman JR. Thrombogenesis in sickle cell disease. J Lab Clin Med. 2001;137(6):398-407.

43. Francis RB. Elevated fibrin D-dimer fragment in sickle cell anemia: evidence for activation of coagulation during the steady state as well as in painful crisis. Haemostasis. 1989;19(2):105-111.

44. Kurantsin-Mills J, Ofosu FA, Safa TK, Siegel RS, Lessin LS. Plasma factor VII and thrombin-antithrombin III levels indicate increased tissue factor activity in sickle cell patients. Br J Haematol. 1992;81(4):539-544.

45. Cappellini MD, Robbiolo L, Bottasso BM, Coppola R, Fiorelli G, Mannucci AP. Venous thromboembolism and hypercoagulability in splenectomized patients with thalassaemia intermedia. Br J Haematol. 2000;111(2):467-473.

46. Born GV, Bergquist D, Arfors KE. Evidence for inhibition of platelet activation in blood by a drug effect on erythrocytes. Nature. 1976;259(5540):233-235

47. Gaarder A, Jonsen J, Laland S, Hellem A, Owren PA. Adenosine diphosphate in red cells as a factor in the adhesiveness of human blood platelets. Nature. 1961;192:531-532.

48. Eltzschig HK, Sitkovsky MV, Robson SC. Purinergic signaling during inflammation. N Engl J Med. 2012;367(24):2322-2333.

49. Jin J, Kunapuli SP. Coactivation of two different G protein-coupled receptors is essential for ADP-induced platelet aggregation. Proc Natl Acad Sci USA. 1998;95(14):8070-8074.

50. Holmsen H, Weiss HJ. Secretable storage pools in platelets. Annu Rev Med. 1979;30:119-134.

51. Rosenberg RD. Actions and interactions of antithrombin and heparin. N Engl J Med. 1975;292(3):146-151.

52. Jakubowski JA, Winters KJ, Naganuma H, Wallentin L. Prasugrel: a novel thienopyridine antiplatelet agent. A review of preclinical and clinical studies and the mechanistic basis for its distinct antiplatelet profile. Cardiovasc Drug Rev. 2007;25(4):357-374.

53. Wright RS, et al. 2011 ACCF/AHA focused update incorporated into the ACC/AHA 2007 Guidelines for the Management of Patients with Unstable Angina/Non-ST-Elevation Myocardial Infarction: a report of the American College of Cardiology Foundation/American Heart Association Task Force on Practice Guidelines developed in collaboration with the American Academy of Family Physicians, Society for Cardiovascular Angiography and Interventions, and the Society of Thoracic Surgeons. J Am Coll Cardiol. 2011;57(19):e215-e367.

54. Niitsu Y, Jakubowski JA, Sugidachi A, Asai F. Pharmacology of CS-747 (prasugrel, LY640315), a novel, potent antiplatelet agent with in vivo P2Y12 receptor antagonist activity. Semin Thromb Hemost. 2005;31(2):184-194.

55. Helms CC, et al. Mechanisms of hemolysis-associated platelet activation. J Thromb Haemost. 2013;11(12):2148-2154.

56. Remijn JA, et al. Role of ADP receptor P2Y(12) in platelet adhesion and thrombus formation in flowing blood. Arterioscler Thromb Vasc Biol. 2002;22(4):686-691.

57. Chen J, López JA. Interactions of platelets with subendothelium and endothelium. Microcirculation. 2005;12(3):235-246.

58. Krishnan S, Siegel J, Pullen G, Hevelow M, Dampier C, Stuart M. Increased von Willebrand factor antigen and high molecular weight multimers in sickle cell disease associated with nocturnal hypoxemia. Thromb Res. 2008;122(4):455-458.

59. Bennewitz MF, Watkins SC, Sundd P. Quantitative intravital two-photon excitation microscopy reveals absence of pulmonary vaso-occlusion in unchallenged Sickle Cell Disease mice. Intravital. 2014;3(2):e29748.

60. Bennewitz MF, et al. Lung vaso-occlusion in sickle cell disease mediated by arteriolar neutrophil-platelet microemboli. JCI Insight. 2017;2(1):e89761.

61. Bennewitz MF, et al. P-selectin-deficient mice to study pathophysiology of sickle cell disease. Blood Adv. 2020;4(2):266-273

62. Sparkenbaugh EM, et al. Thrombin activation of PAR-1 contributes to microvascular stasis in mouse models of sickle cell disease. Blood. 2020;135(20):1783-1787.

63. Vats R, et al. Platelet Extracellular Vesicles Drive Inflammasome-IL-1 $\beta$-Dependent Lung Injury in Sickle Cell Disease. Am J Respir Crit Care Med. 2020;201(1):33-46.

64. Wajih N, et al. Potential therapeutic action of nitrite in sickle cell disease. Redox Biol. 2017;12:1026-1039.

65. Conran N, Almeida CB. Hemolytic vascular inflammation: an update. Rev Bras Hematol Hemoter. 2016;38(1):55-57.

66. Atkinson BT, Jasuja R, Chen VM, Nandivada P, Furie B, Furie BC. Laser-induced endothelial cell activation supports fibrin formation. Blood. 2010;116(22):4675-4683.

67. Araki H, Nishi K, Ishihara N, Okajima K. Inhibitory effects of activated protein C and heparin on thrombotic arterial occlusion in rat mesenteric arteries. Thromb Res. 1991;62(3):209-216.

68. Ohno K, Tomizawa A, Mizuno M, Jakubowski JA, Sugidachi A. Prasugrel, a Platelet P2Y12 Receptor Antagonist, Improves Abnormal Gait in a Novel Murine Model of Thrombotic Hindlimb Ischemia. J Am Heart Assoc. 2016;5(4):e002889. 
69. Wong CH, Jenne CN, Petri B, Chrobok NL, Kubes P. Nucleation of platelets with blood-borne pathogens on Kupffer cells precedes other innate immunity and contributes to bacterial clearance. Nat Immunol. 2013;14(8):785-792.

70. Vats R, et al. Platelet Extracellular Vesicles Drive Inflammasome-IL-1 $\beta$-Dependent Lung Injury in Sickle Cell Disease. Am J Respir Crit Care Med. 2020;201(1):33-46. 